\title{
Events before the diagnosis of a pneumothorax in ventilated neonates
}

\author{
M Watkinson, I Tiron
}

\begin{abstract}
Aim-To examine the relation of overventilation and other clinical events to the development of pneumothoraces in ventilated neonates.

Methods-A case-control study.

Results-Fifty three $(8.7 \%)$ of 606 ventilated neonates developed a pneumothorax. Eighteen (34\%) cases and $23(43 \%)$ controls were unintentionally overventilated $\left(\mathrm{PaCO}_{2}<4 \mathrm{kPa}\right)$ at some time before the pneumothorax developed in the cases (odds ratio $(\mathrm{OR})=0.78,95 \%$ confidence interval (CI) 0.48 to 1.27 ). In the three hours before the diagnosis of pneumothorax, more cases than controls were reintubated $(21 / 53 v 4 / 53$; OR $=5.25,95 \%$ CI 1.9 to 14.3), and also in seven cases (one control) the mean airway pressure was increased, whereas in nine controls (no cases) it was reduced $\left(\chi^{2}=12.0, \mathrm{df}=2\right.$, $p=0.001)$. Seven of 18 neonates diagnosed by transillumination had undergone no clinical procedures before diagnosis compared with five of 35 diagnosed radiologically $(\mathrm{OR}=2.7,95 \% \mathrm{CI} 1.0$ to 7.4$)$.

Conclusions-Unintentional overventilation was not associated with pneumothoraces. In the hours before diagnosis, there was increased clinical intervention, including reintubation; this was less so in those diagnosed by transillumination. The study did not elucidate whether such interventions caused the pneumothorax or were secondary to a failure to diagnose it. (Arch Dis Child Fetal Neonatal Ed 2001;85:F201-F203)
\end{abstract}

Keywords: pneumothorax; ventilation; transillumination

Pneumothoraces occur in critically ill ventilated neonates despite treatment with antenatal corticosteroids, ${ }^{1}$ surfactant, ${ }^{23}$ and less aggressive ventilation in persistent pulmonary hypertension of the newborn. ${ }^{4}$ The value of new ventilatory techniques in reducing air leaks is debated. ${ }^{56}$ Pneumothorax during respiratory distress is associated with an increased risk of intraventricular haemorrhage, ${ }^{7}$ chronic lung disease, and death. ${ }^{8}$

The incidence of pneumothoraces varies between units with similar populations of infants. There is concern about overventilation, as permissive hypercapnoea has been associated with favourable respiratory outcomes in infants $>700 \mathrm{~g}^{9}$ or $>25$ weeks. $^{10}$ Aware that some neonates on our unit were inadvertently overventilated early in their respiratory illness, we reviewed the relation between the hypocapnoea so caused and the development of pneumothoraces.

We also reviewed events before the diagnosis of pneumothorax to see if a recognisable pattern of clinical problems or treatments occurred repeatedly. If so, would recognition of that pattern in the future accelerate the diagnosis of pneumothorax?

\section{Patients and methods}

We reviewed neonates who developed at least one pneumothorax during ventilation in the first 14 days of life on our unit from January 1995 to December 1999. Taking the next born baby who was ventilated without developing an air leak and had a gestation within two weeks and a birth weight within $250 \mathrm{~g}$ of the case created a matched control.

A $\mathrm{PaCO}_{2}<4 \mathrm{kPa}$ was considered the threshold for diagnosing overventilation. To assess this, the minimum $\mathrm{PaCO}_{2}$ for each case at any time from birth to the diagnosis of pneumothorax was noted, as was the minimum $\mathrm{PaCO}_{2}$ of the matched control before that same age.

The notes and radiographs of all babies were reviewed to confirm the diagnoses. Resuscitation procedures, respiratory diagnoses, ventilatory details, and arterial blood gases were recorded up to the age of diagnosis in the case. For the preceding three hours, procedures such as suction, reintubation, bagging, and cardiac massage were retrieved from the notes, charts, and cotside monitoring system. The diagnosis was either by transillumination or chest radiography. The three hour period was chosen because it exceeded both the longest time taken to obtain a chest radiograph (one hour) and the median delay in pneumothorax diagnosis (127 minutes) reported by McIntosh et al. ${ }^{11}$

All babies were ventilated using a Drager 8000 Neonatal Ventilator (Drager Ltd, Hemel Hempstead, UK). Initial ventilation was often determined by randomisation into a continuing multicentre trial or by clinician's choice when trial consent was not obtained. During the study period, high frequency oscillation was used as a "rescue therapy" if the peak inspiratory pressure on conventional ventilation was $>20 \mathrm{mbar}$, and/or if the $\mathrm{PaCO}_{2}$ was $>8$ $\mathrm{kPa}$ and $\mathrm{pH}<7.25$. Synchronous intermittent mandatory ventilation was used as a weaning mode. Surfactant was given at delivery to all babies $\leqslant 28$ weeks and to babies $\leqslant 30$ weeks intubated for resuscitation, or early after intubation for ventilation in worsening respiratory distress. Antenatal dexamethasone was given to mothers between 23 and 34 weeks gestation. 
Table 1 Modes of ventilation

\begin{tabular}{|c|c|c|c|}
\hline & Cases $(n=53)$ & Controls $(n=53)$ & $\begin{array}{l}\text { Cases } v \text { controls } \\
\text { Odds ratio }(95 \% \\
\text { CI) or significance }\end{array}$ \\
\hline \multicolumn{4}{|l|}{ At age of pneumothorax } \\
\hline SIPPV & 23 & 17 & \\
\hline SIMV & 3 & 13 & \\
\hline IPPV & 7 & 5 & $\chi^{2}=20.9$ \\
\hline $\mathrm{HFO}$ & 13 & 5 & $\mathrm{df}=6$ \\
\hline CPAP & 7 & 4 & $\mathrm{p}<0.002$ \\
\hline None & 0 & 8 & \\
\hline Dead & 0 & 1 & \\
\hline $\mathrm{PIP}>20 \mathrm{mbar}$ & 15 & 11 & NS \\
\hline $\mathrm{Ti}>0.3 \mathrm{sec}$ & 13 & 18 & \\
\hline Rate $<60$ beats $/ \mathrm{min}$ & 2 & 4 & \\
\hline \multicolumn{4}{|l|}{ Previous ventilation } \\
\hline No change & 36 & 35 & \\
\hline $\mathrm{SIPPV} \rightarrow \mathrm{HFO}$ & 9 & 2 & $\mathrm{OR}=4.5$ (1.02 to \\
\hline & & $\begin{array}{l}2 \text { went on to } \mathrm{HFO} \text {, } \\
9 \text { went on to } \\
\text { SIMV, } \\
\text { CPAP or headbox } \\
\mathrm{O}_{2}\end{array}$ & 19.9) \\
\hline $\begin{array}{l}\text { SIPPV } \rightarrow \text { SIMV or } \\
\text { extubation }\end{array}$ & 0 & 9 & $\mathrm{p}=0.0013^{\star}$ \\
\hline CPAP & 2 & 0 & \\
\hline $\mathrm{HFO}$ & 2 & 0 & \\
\hline IPPV & 2 & 3 & \\
\hline SIMV & 2 & 4 & \\
\hline
\end{tabular}

^Fisher's exact probability.

SIPPV, Synchronous intermittent positive pressure ventilation; SIMV, synchronous intermittent mandatory ventilation; IPPV, intermittent positive pressure ventilation; HFO, high frequency oscillation; CPAP, continuous positive airway pressure; PIP, peak inspiratory pressure.

Table 2 Ventilation changes and procedures in the three hours before the diagnosis of a pneumothorax

\begin{tabular}{llll}
\hline & $\begin{array}{l}\text { Cases } \\
(n=53)\end{array}$ & $\begin{array}{l}\text { Controls } \\
(n=53)\end{array}$ & $\begin{array}{l}\text { Cases v controls Odds ratio } \\
(95 \% \text { CI }) \text { or significance }\end{array}$ \\
\hline $\begin{array}{l}\text { MAP up } \\
\text { MAP same }\end{array}$ & 7 & 1 & $\chi^{2}=12.0, \mathrm{df}=2, \mathrm{p}=0.001$ \\
MAP down & 46 & 43 & \\
Dead & 0 & 9 & $5.25(1.9$ to 14.3$)$ \\
Reintubated & 0 & 1 & $\mathrm{p}=0.03^{\star}$ \\
Endotracheal tube too far & 5 & 4 & \\
Bagged only & 3 & 0 & \\
Suction only & 7 & 1 & \\
Chest compression & 2 & 7 & \\
Needling of chest & 4 & 0 & \\
Chest radiograph & 3 & 0 & \\
& & 3 & \\
No clinical procedures & 12 & 30 &
\end{tabular}

^Fisher's exact probability.

MAP, Mean airway pressure.

\section{Results}

Fifty three (8.7\%) of 606 babies developed one or more pneumothoraces during ventilation or continuous positive airway pressure in the first 14 days of life. The median (range) gestation of both cases and controls was 29 (23-41) weeks, and their birth weights were 1200 (590-4000) $\mathrm{g}$ and 1215 (615-4140) g respectively. Thirty nine in each group were mask or tube ventilated at birth. Thirty nine cases and 41 controls had surfactant deficient respiratory distress syndrome as their primary diagnosis; five cases and four controls developed meconium aspiration syndrome.

MODES OF VENTILATION

Table 1 shows ventilation at the diagnosis of the pneumothorax and before that time. The significant difference between the groups at the age of diagnosis was mainly attributable to an excess of high frequency oscillation in the cases and weaning modes in the controls. Thirty six $(68 \%)$ cases and $35(66 \%)$ controls had not

\section{Key messages}

- Brief inadvertent overventilation was not associated with pneumothoraces

- There was a cluster of clinical procedures before the diagnosis of a pneumothorax. This included reintubation and increases in airway pressure. This study did not establish whether these procedures caused pneumothoraces or were undertaken because an undiagnosed pneumothorax was already causing clinical deterioration.

changed ventilatory mode at all. However, nine cases but only two controls had been changed from synchronous intermittent positive pressure ventilation (SIPPV) to high frequency oscillation (OR 4.5, 95\% CI 1.02 to 19.9), whereas nine controls and no cases had been changed from SIPPV to a weaning mode of ventilation or extubation $(p=0.0013)$.

HYPOCAPNOEA

The median (range) minimum $\mathrm{PaCO}_{2}$ at any time before diagnosis of pneumothorax was $4.45(1.83-8.00) \mathrm{kPa}$ in the cases and 4.00 (1.81 to $>15.00) \mathrm{kPa}$ in the controls (difference not significant). It had not been measured in two cases and one control. Eighteen cases and 23 controls had been overventilated to a minimum $\mathrm{PaCO}_{2}<4 \mathrm{kPa}(\mathrm{NS}, \mathrm{OR}=0.78$, $95 \%$ CI 0.48 to 1.27 ).

VENTILATION AND PROCEDURES IN THE THREE HOURS BEFORE DIAGNOSIS

Table 2 shows that in $46(87 \%)$ cases and 43 $(81 \%)$ controls the mean airway pressure had been held constant. However, in seven cases but only one control the mean airway pressure had increased, whereas in no cases but in nine controls it had been reduced $\left(\chi^{2}=12, \mathrm{df}=2\right.$, $\mathrm{p}=0.001)$.

Twenty one cases but only four controls were reintubated $(\mathrm{OR}=5.25,95 \%$ CI 1.9 to 14.3$)$. In five cases but no controls an endotracheal tube had been inserted beyond the carina $(p=0.03)$. Procedures such as chest radiography, bagging, suction, chest compression, and needling of the chest were not performed significantly more often in the cases, but the clinical significance, particularly of needling the chest, is apparent. In significantly fewer cases than controls $(12 / 53 v 30 / 53)$, there had been no procedures at all $(\mathrm{OR}=0.4,95 \% \mathrm{CI}$ 0.23 to 0.69 ).

Seven of 18 babies diagnosed by transillumination had none of these clinical procedures in the three hours before diagnosis, compared with five of 35 diagnosed radiologically $(\mathrm{OR}=2.7,95 \%$ CI 1.0 to 7.4$)$. Twelve $(34 \%)$ of the 35 pneumothoraces diagnosed radiologically were under tension.

\section{Discussion}

Over five years, $8.7 \%$ of ventilated babies developed at least one pneumothorax during the first 2 weeks of life. This is similar to the 
rates of $14 \%,{ }^{12} 10.3 \%$ and $13.4 \%{ }^{5}$ recently reported elsewhere in the United Kingdom.

This study started after recognition that some babies who developed a pneumothorax had been accidentally overventilated. Thirty three $(62 \%)$ of our 53 cases had a minimum $\mathrm{PaCO}_{2}<5 \mathrm{kPa}$, and in $18(34 \%)$ it was $<4 \mathrm{kPa}$. A clear association between overventilation and pneumothorax was expected, but not found. This hypocarbia was similar to three reports on ventilated babies on day 1 of life: one of a 3 rd centile for transcutaneous $\mathrm{PCO}_{2}$ of $2.0-3.1 \mathrm{kPa}$ depending on gestation ${ }^{11}$; one of median $\mathrm{PaCO}_{2}$ values of $3.87 \mathrm{kPa}^{12}$; and one of $\mathrm{PaCO}_{2}$ levels $<3.33 \mathrm{kPa}$ in $31.4 \%$ of such babies. ${ }^{13}$

At the time of diagnosis the pneumothorax group were being ventilated harder, with a quarter on "rescue" high frequency oscillation, and with a trend to increasing pressures. This contrasted with the tendency to wean the controls. Although it is tempting to attribute the pneumothoraces to changes in ventilation mode or pressure, no such conclusions should be drawn. Was the degree of ventilation a proxy measure for the disease severity, and were the pneumothoraces associated primarily with that rather than any ventilatory parameter? Ventilation could also have been increased because an undiagnosed pneumothorax was already developing. Similarly, the study has not clarified whether the babies were reintubated and had their chests needled because a pneumothorax was already present or whether some of these procedures actually caused a pneumothorax. The key message is to transilluminate for a pneumothorax in deteriorating ventilated babies before reintubation or other procedures.

The diagnosis was perhaps quicker when the chest was transilluminated, as significantly fewer of these babies had other procedures before diagnosis. However, it may have been that pneumothoraces diagnosed on transillumination were obvious because they were bigger or under tension. More worrying is that $12(34 \%)$ pneumothoraces diagnosed radiologically were under tension; they here should have been easily and safely diagnosed by transillumination. It should be used to screen for large life threatening pneumothoraces. ${ }^{14}$

In 60 months, only 53 babies developed pneumothoraces during early ventilation. As the incidence falls, opportunities for junior doctors to diagnose and treat pneumothoraces diminish. The non-curative interventions such as intubation and suction indicated that pneumothorax was not always considered and diagnosed promptly. Trend monitoring of changes in transcutaneous $\mathrm{PCO}_{2}$ may be a diagnostic aid. ${ }^{11}$ Animal models can be used to gain confidence in chest drain insertion. ${ }^{15}$

We conclude that brief overventilation was not associated with pneumothoraces. A pattern of increasing ventilation and an apparent need to reintubate or initiate resuscitative procedures in ventilated babies must be accompanied by a prompt search for a pneumothorax. This should include transillumination of the chest. This is so whether the procedures we described above preceded the pneumothorax or not. Failure to transilluminate may result in inappropriate procedures and the development of tension pneumothoraces.

1 Crowley P. Prophylactic corticosteroids for preterm birth. Cochrane Database of Systematic Reviews 2000:1.

2 Morley C. Systematic review of prophylactic v rescue Morley C. Systematic review of prophylactic v rescue
surfactant. Arch Dis Child Fetal Neonatal Ed 1997;77:F704 .

3 Halliday H L. Natural vs. Synthetic surfactants in neonatal respiratory distress syndrome. Drugs 1996:51;226-37.

4 Wung JT, James S, Kilchevsky E. Management of infants with severe respiratory failure and persistence of fetal circulation without hyperventilation. Pediatrics 1985;76:48894.

5 Baumer H. International randomised controlled trial of patient triggered ventilation in neonatal respiratory distress syndrome. Arch Dis Child Fetal Neonatal Ed 2000;82:F5-10

6 Henderson-Smart DJ, Bhuta T, Cools F, et al. Effective high frequency oscillation ventilation versus conventional ventilation for acute pulmonary dysfunction in preterm infants. Cochrane Database of Systematic Reviews 2000:1.

7 Hill A, Perlman JM, Volpe JJ. Relationship of pneumothorax to the occurrence of intraventricular haemorrhage in preterm newborns. Pediatrics 1982;69:144-9.

8 Powers WF, Clemens JD. Prognostic implications of age at detection of air leak in very low birthweight infants requiring ventilatory support. $\mathcal{F}$ Pediatr 1993;123:611-17.

9 Avery ME, Tooley WH, Keller JB, et al. Is chronic lung disease in low birth infants preventable? A survey of eight centers. Pediatrics 1987;79:26-30.

10 Kamper J, Wulff K, Larsen C, et al. Early treatment with continuous positive airway pressure in very low birthweight infants. Acta Paediatr 1993;82:193-7.

11 McIntosh N, Becher JC, Stenson B, et al. The clinical diagnosis of pneumothorax is late: use of trend data and decision support might allow preclinical detection. Pediatr Res 2000;48:408-15.

12 Shaw NJ, Cooke RWI, Gill AB, et al. Randomised trial of routine versus selective paralysis during ventilation for neonatal respiratory distress syndrome. Arch Dis Child 1993;69:479-82.

13 Luyt K, Wright D, Baumer JH. Randomised study comparing extent of hypocarbia in preterm infants during conventional and trigger ventilation. Arch Dis Child Fetal Neonatal Ed 2000;84:F14-17.

14 Kuhns LR, Bednarek FJ, Wyman ML, et al. Diagnosis of pneumothorax or pneumomediastinum in the neonate by transillumination Pediatrics 1975;56:355-60.

15 Hourihane JO, Crawshaw PA, Hall MA. Neonatal chest drain insertion: an animal model. Arch Dis Child Fetal Neonatal Ed 1995;72:F123-4. 